\title{
Otto Zwierlein
}

Die Ovid- und Vergil-Revision in tiberischer Zeit

$$
\begin{aligned}
& W \\
& D E \\
& G
\end{aligned}
$$




\title{
Untersuchungen zur antiken Literatur und Geschichte
}

\author{
Herausgegeben von \\ Winfried Bühler, Peter Herrmann und Otto Zwierlein
}

Band 57

Walter de Gruyter · Berlin · New York

1999 


\title{
Die Ovid- und Vergil-Revision in tiberischer Zeit
}

\author{
Band I \\ Prolegomena
}

\author{
von \\ Otto Zwierlein
}

Walter de Gruyter · Berlin · New York 


\section{(0) Gedruckt auf säurefreiem Papier, das die US-ANSI-Norm über Haltbarkeit erfüllt.}

\section{Die Deutsche Bibliothek - CIP.Einheitsaufnabme}

\section{Zwierlein, Otto:}

Die Ovid- und Vergil-Revision in tiberischer Zeit / von Otto

Zwierlein. - Berlin ; New York : de Gruyter

Bd. 1. Prolegomena. - 1999

(Untersuchungen zur antiken Literatur und Geschichte ; Bd. 57)

ISBN 3-11-016635-6

(C) Copyright 1999 by Walter de Gruyter Gmbh \& Co. KG, D-10785 Berlin

Dieses Werk einschließlich aller seiner Teile ist urheberrechtlich geschützt. Jede Verwertung außerhalb der engen Grenzen des Urheberrechtsgesetzes ist ohne Zustimmung des Verlages unzulässig und strafbar. Das gilt insbesondere für Vervielfältigungen, Übersetzungen, Mikroverfilmungen und die Einspeicherung und Verarbeitung in elektronischen Systemen.

Druck und Buchbinderische Verarbeitung: Strauss Offsetdruck, Mörlenbach 
MEINEM

BONNER

OBERSEMINAR 
